\title{
Morphological Variations and Measurements of the Caudate Lobe of the Human Liver: A Cadaveric Study
}

\author{
IBRAHIM HASSAN IBRAHIM, M.D. \\ Department of Human Anatomy and Embryology, Faculty of Medicine, Zagazig University, Sharkia, Egypt
}

\begin{abstract}
Background: The caudate lobe is an anatomic segment of the human liver and has a great clinical importance in hepatic diseases.

Aim of Study: The aim of this study was to evaluate the morphological variations and anatomical measurements of the caudate lobe of the human liver that could be important in interpretation of its pathological conditions.
\end{abstract}

Material and Methods: Measurements and morphological analysis of the caudate lobe of the human liver were determined in 56 formalin fixed human liver specimens in the Anatomy and Embryology Department, Faculty of Medicine, Zagazig University, Egypt.

Results: The common shape of the caudate lobe was rectangular. The mean length of the caudate lobe was $57.45 \pm 4.74 \mathrm{~mm}$ while the mean of its transverse diameter was $27.49 \pm 2.82 \mathrm{~mm}$. The mean of transverse diameter of the right lobe of the liver was $90.58 \pm 7.76 \mathrm{~mm}$ and also, the mean of caudate lobe-right lobe (CL/RL) ratio was $0.30 \pm 0.03$.

Conclusion: Variable shapes of the caudate lobe of the liver were present. The ratio of the transverse diameter of caudate lobe to that of the right lobe of the liver ranged between $0.22-0.38$. The collected data in this study may be valuable to aid the surgeons in proper planning of hepatic surgery and to avoid the misdiagnosis of hepatic diseases.

Key Words: Liver-Caudate-Accessory fissures - Variations.

\section{Introduction}

THE human liver is located in the right hypochondrium, epigastrium and extends into the left hypochondrium and has five surfaces (anterior, superior, right, inferior and posterior surfaces) [1]. The liver is divided by ligamentum venosum, ligamentum teres and falciform ligament into right, left, quadrate and caudate lobes, also the liver is formed of eight functional segments [2]. Chavan and Wabale [3] stated that anatomically, the caudate lobe belongs

Correspondence to: Dr. Ibrahim Hassan Ibrahim, E-Mail: ebrahimelazony5555@yahoo.com. to the right lobe of the liver but physiologically it belongs to the left lobe. Patil et al., [4] added that the liver is variable in size according to the age, sex and human body size. The caudate lobe is an anatomic distinct segment of the liver, located on its posterior surface and bounded by inferior vena cava on its right side and groove for ligamentum venosum on its left side [3,5]. Inferiorly, the caudate lobe of the liver shows a lateral caudate process that extends obliquely to the right lobe of the liver and a medial small projection called papillary process [6] . Lobectomy of caudate lobe of the liver is the most appropriate treatment for its localised benign tumors [7]. The caudate lobe shows some morphological variations and only few studies discussed these surface variations $[\mathbf{3 , 4 , 8}$. Although, there is advancement in the imaging techniques as the magnetic resonance imaging in evaluation of the human liver, studies of the anatomical features of the cadaveric liver are still highly valuable in recording its anatomical variations $[\mathbf{9 , 1 0 ]}$. In some cases, the papillary process of caudate lobe was large and during imaging it can simulate mass in the head of pancreas or periportal lymph nodes [11]. The aim of the present work was to study the morphological variations and anatomical measurements of the caudate lobe of the human liver to aid radiologists and surgeons for proper planning of hepatic surgery. Also, the ratio of the transverse diameter of the caudate lobe to that of the right lobe of the liver (CL/RL ratio) was determined that is important in diagnosis of the liver cirrhosis.

\section{Material and Methods}

The study was implemented on 56 human liver specimens (formalin fixed) available in the dissection room and museum of the Anatomy and Embryology Department, Faculty of Medicine, Zagazig University, Egypt. This study was approved by Institutional Review Board, Faculty of Medicine, 
Zagazig University (ZU-IRB\#5171) and done between February and March (2019).

Inclusion criteria: All cadaveric liver specimens included in this study had normal anatomical features and the weight of each liver was ranged from $1.2-1.8 \mathrm{~kg}$.

Exclusion criteria: The cadaveric liver specimens had features of damage, hepatic surgery or tumours were excluded from this study.

The caudate lobe was studied for its size, shape, variations in the papillary and caudate processes and the presence of fissures. To determine the transverse diameter of caudate lobe, the midpoint of hepatic part of inferior vena cava (I.V.C.) was used as a reference point for the right lateral margin of the caudate lobe [3] as in Fig. (1). The transverse diameter of the remaining part of right lobe of the liver was recorded by using the same reference point [3] as in Fig. (2) and the ratio of transverse diameter of caudate lobe to that of the right lobe (CL/RL ratio) of the liver was determined. The inferior level of hepatic part of I.V.C. (or its groove) was determined at the posterior border of caudate process of the caudate lobe of the liver $[\mathbf{1 2 , 1 3}]$. The length of the caudate lobe was measured from its lower border above the porta hepatis and portal vein [14] as in Fig. (3). The previous measurements were recorded in $\mathrm{mm}$ by electronic digital caliber (three readings were noted for each parameter then the maximum reading was recorded).

Statistical analysis: SPSS (Version 22, IBM Corp. Armonk, New York, USA) program was used for calculating the data of caudate lobe of the human liver included the percentage of its different shapes, presence of accessory fissures and variations of caudate and papillary processes. Measurements of caudate lobe and transverse diameter of right lobe of the liver were expressed in the form of mean \pm standard deviation (SD), minimum and maximum for each parameter.

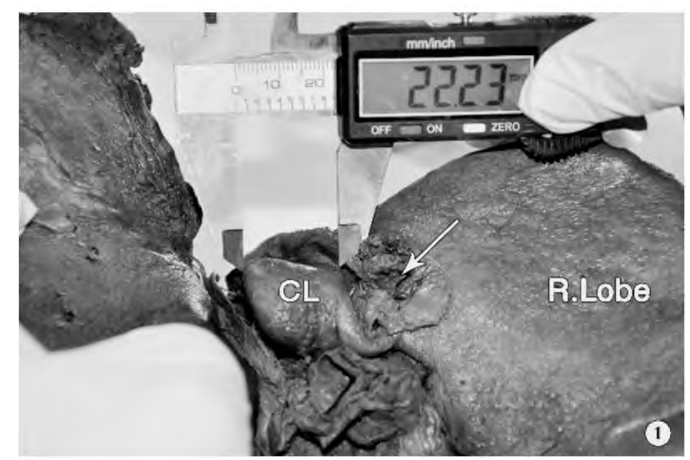

Fig. (1): A photograph showing the method of measurement of the transverse diameter of caudate lobe (CL) of the human liver (Arrow referred to inferior vena cava).

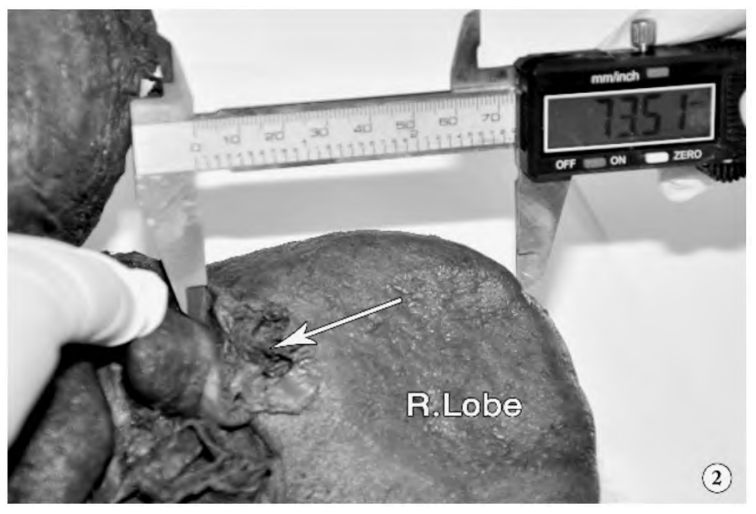

Fig. (2): A photograph showing the method of measurement of the transverse diameter of right lobe of human liver (Arrow referred to inferior vena cava).

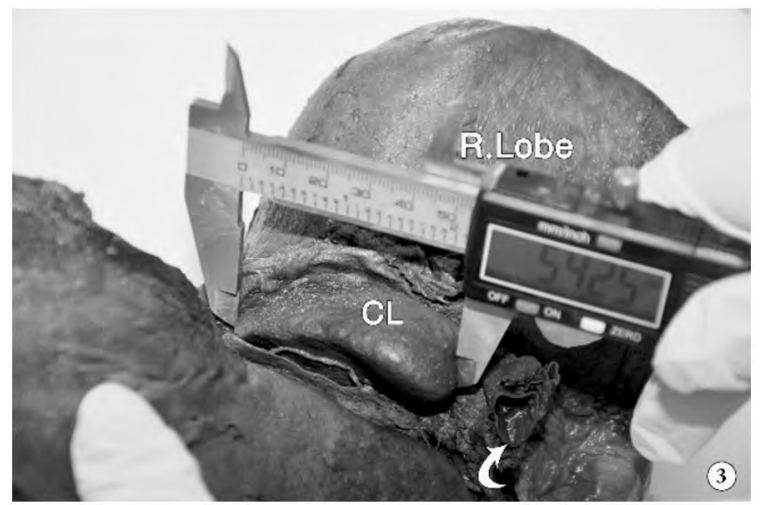

Fig. (3): A photograph showing the method of measurement of the length of caudate lobe (CL) of human liver (Curved arrow referred to the porta hepatis).

\section{Results}

In this research, the caudate lobe showed various shapes. The caudate lobe was rectangular in 41 liver specimens (73.21\%), triangular in 12 specimens $(21.43 \%)$ and irregular in 3 specimens $(5.36 \%)$ (Figs. 4,5,6 respectively and Graph 1 ).

The length of the caudate lobe ranged between 46.85-69.63mm (its mean length was $57.45 \pm$ $4.74 \mathrm{~mm}$ ) and its transverse diameter ranged between 22.16-37.16mm (its mean transverse diameter was $27.49 \pm 2.82 \mathrm{~mm}$ ). The transverse diameter of the right lobe of the liver ranged between 73.51$115.12 \mathrm{~mm}$ and its mean diameter was $90.58 \pm$ $7.76 \mathrm{~mm}$. The ratio between transverse diameter of the caudate lobe and that of the right lobe of the liver ranged between $0.22-0.38$ and its mean was $0.30 \pm 0.03$. In 15 liver specimens $(26.79 \%$ of total number of liver specimens), there was a longitudinal fissure that extended upwards from the lower border of caudate lobe (Figs. 7,8). In 8 liver specimens (14.29\% of total number of liver specimens) accessory fissures were present between the caudate process of the liver and the duodenal impression (Figs. 4,8). Out of these 8 specimens, two specimens were associated also with fissure for liga- 
mentum teres on the anterior surface of the liver (Figs. 9A-9B). Also, out of these 8 specimens, in 3 liver specimens there was association between the longitudinal fissure in the caudate lobe with accessory fissure present between the caudate process of the liver and the duodenal impression (Fig. 8). In the present study, the papillary process was prominent and seen in 24 liver specimens (42.86\% of total number of liver specimens) (Figs. 4,7 ) and out of these 24 liver specimens, only three liver specimens showed a large papillary process (Figs. 10,11). Also, in all liver specimens the caudate process was seen as shown in Figs. $(4,7,8)$.

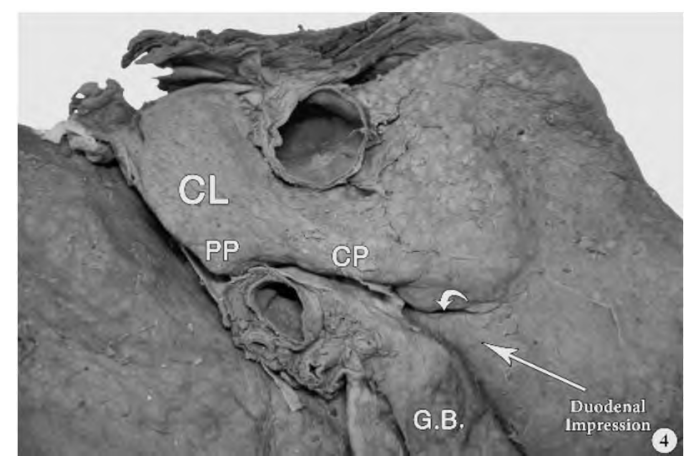

Fig. (4): A photograph showing rectangular shaped caudate lobe $(\mathrm{CL})$ of the human liver. Accessory fissure (curved arrow) is seen between caudate process (CP) of the caudate lobe and duodenal impression (arrow). The papillary process (PP) is present and also the gall bladder (G.B.) is present in its fossa on the inferior surface of right lobe of the liver.

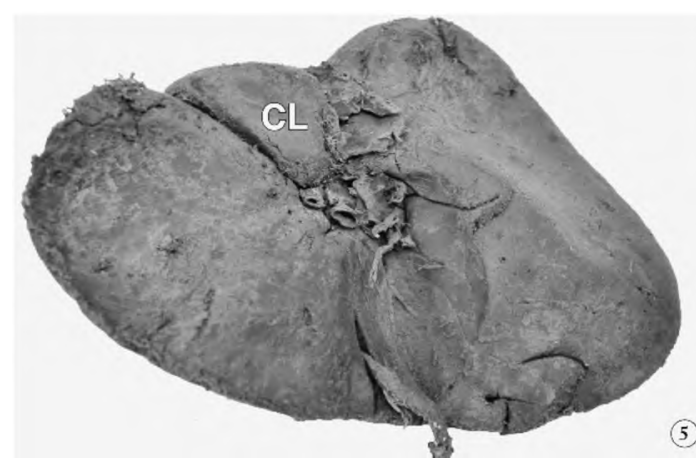

Fig. (5): A photograph showing triangular shaped caudate lobe $(\mathrm{CL})$ of the human liver.

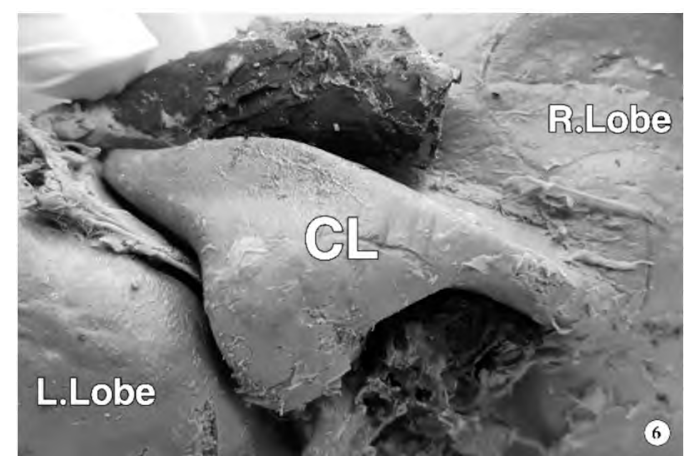

Fig. (6): A photograph showing irregular shaped caudate lobe (CL) of the human liver.

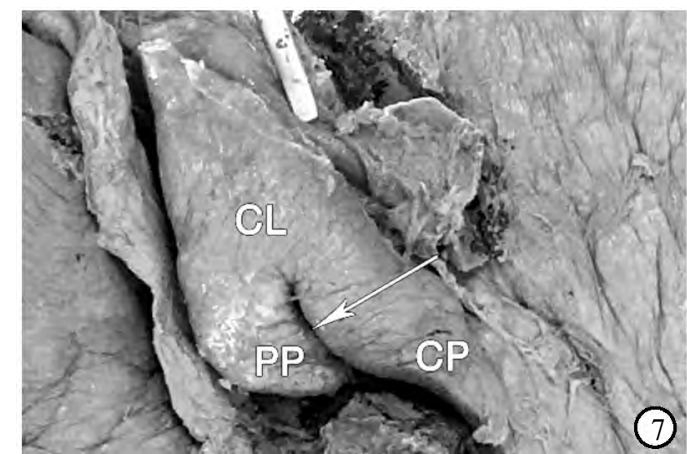

Fig. (7): A photograph showing a longitudinal fissure (arrow) extending upwards from the lower border of caudate lobe (CL). Papillary process (PP) and caudate process (CP) were prominent

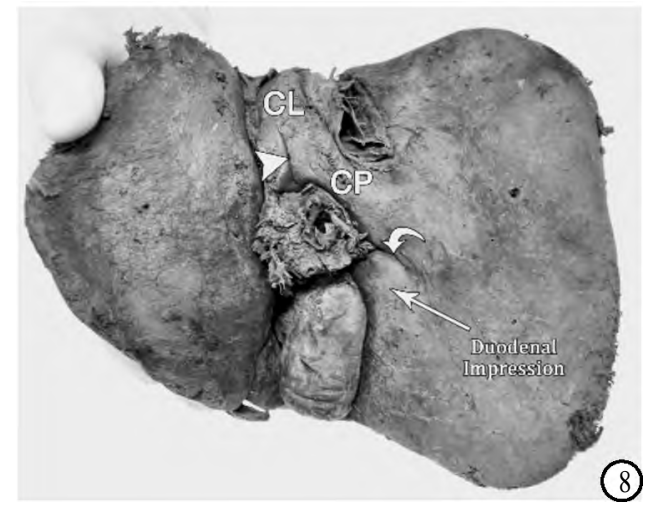

Fig. (8): A photograph showing a longitudinal fissure (arrow head) extending upwards from the lower border of the caudate lobe of the liver (CL) and is associated with accessory fissure (curved arrow) that is present between the caudate process (CP) of the liver and the duodenal impression (arrow).
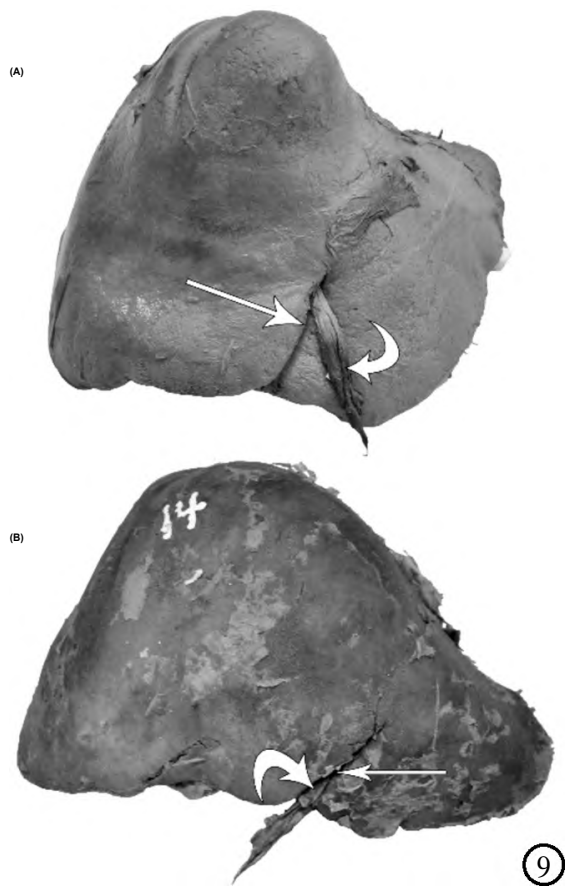

Fig. (9) (A\&B): Photographs showing fissure (arrow) for ligamentum teres (curved arrow) on the anterior surface of the liver. 


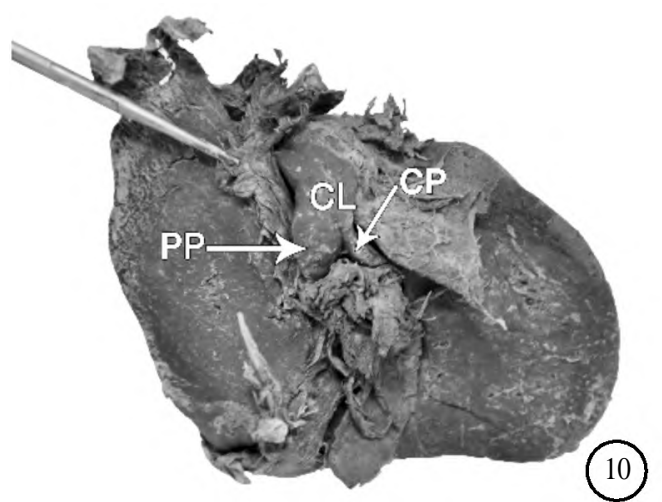

Fig. (10): A photograph showing large papillary process (PP) of the caudate lobe (CL) directed toward the porta hepatis. The caudate process $(\mathrm{CP})$ is present.

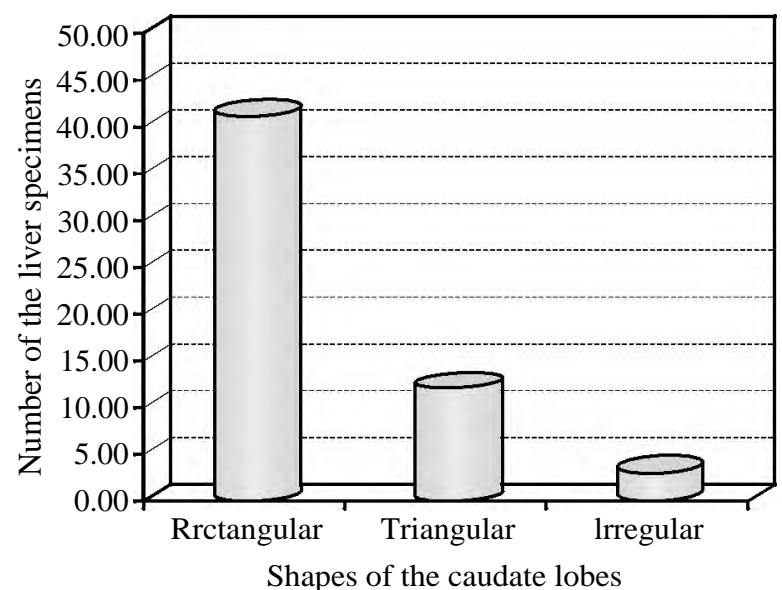

Graph (1): A bar chart showing frequency of different shapes of the caudate lobes of the studied human livers.

\section{Discussion}

During the third week of foetal life, the liver starts its organogenesis [15]. Although the liver has a complex development but its gross abnormalities are very rare [16]. The caudate lobe has clinical importance due to its separate biliary drainage and blood supply, so it has paradoxical behaviour in comparison with the remaining parts of the liver as in liver cirrhosis [14]. In the present study the midpoint of hepatic part of IVC used as a reference

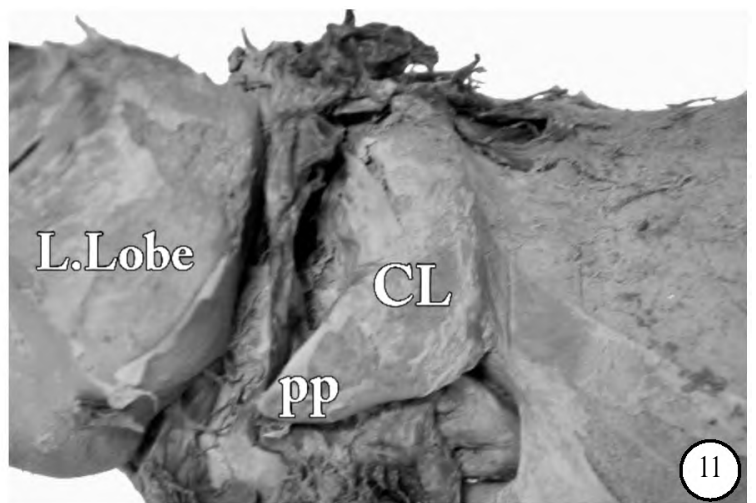

Fig. (11): A photograph showing large papillary process (PP) of the caudate lobe (CL) directed toward the left lobe of the liver.

point for determination of the right margin of the caudate lobe of the liver and measurement of transverse diameters of both caudate lobe and the remaining part of right lobe of the liver then determination of CL/RL ratio. The midpoint of hepatic part of IVC is an ideal reference point as it remains unchanged even in the presence of narrowing or widening of IVC [3]. In a study by Giorgio et al., [17] used the lateral right margin of the main portal vein at its bifurication as a reference point for determination of the right margin of caudate lobe of the liver while Chavan and Wabale [3] revealed that the maximum transverse diameter of different shapes of the caudate lobe was present at a level higher than the main portal vein. Also, in cases of liver cirrhosis dilatation of portal vein due to portal hypertension may occur, so assessment of the maximum transverse diameter of caudate lobe by using the lateral right margin of the main portal vein as a reference point may give a false reading [3]. In a study conducted on 54 livers, there was absence of caudate lobe of the liver in $7.41 \%$ of the liver specimens [18]. In the present study, there were variations in the shapes of the caudate lobes of the livers and the percentages of these variations were compared with relevant studies as shown in Table (1).

Table (1): Showing the various shapes of the caudate lobe of the liver specimens in different studies.

\begin{tabular}{lcccccc}
\hline $\begin{array}{c}\text { Shape of } \\
\text { caudate lobes }\end{array}$ & $\begin{array}{c}\text { Sahni et al. [8] } \\
\text { (200 livers) }\end{array}$ & $\begin{array}{c}\text { Joshi et al. [6] } \\
\text { (90 livers) }\end{array}$ & $\begin{array}{c}\text { Chavan and } \\
\text { Wabale [3] } \\
\text { (50 livers) }\end{array}$ & $\begin{array}{c}\text { Sarala et al. [5] } \\
\text { (100 livers) }\end{array}$ & $\begin{array}{c}\text { Arora et al. [14] } \\
\text { (36 livers) }\end{array}$ & $\begin{array}{c}\text { Present study } \\
\text { (56 livers) }\end{array}$ \\
\hline $\begin{array}{l}\text { Rectangular } \\
\text { Triangular }\end{array}$ & $94.5 \%$ & $58 \%$ & $48 \%$ & $48 \%$ & $91.66 \%$ & $73.21 \%$ \\
$\begin{array}{l}\text { Irregular } \\
\text { Elongated }\end{array}$ & $1 \%$ & $8 \%$ & $4 \%$ & $12 \%$ & $5.55 \%$ & $21.43 \%$ \\
Pear & - & $20 \%$ & & $16 \%$ & & $5.36 \%$ \\
Others & $4.5 \%$ & $10 \%$ & $26 \%$ & $18 \%$ & $2.77 \%$ & - \\
\hline
\end{tabular}


The differences in the percentages of the variations of the shapes of the caudate lobes of the livers may be due to the differences in the number of the liver specimens under each study [3]. In the present work, the length of the caudate lobe ranged between 46.85$69.63 \mathrm{~mm}$ while its transverse diameter ranged between $22.16-37.16 \mathrm{~mm}$. Also, the transverse diameter of the remaining part of the right lobe of the liver ranged between $73.51-115.12 \mathrm{~mm}$ and the ratio between transverse diameter of the caudate lobe and that of the right lobe of the liver (CL/RL ratio) ranged between 0.22-0.38. When the liver shrinks as in the liver cirrhosis, compensatory hypertrophy of the caudate lobe of the liver occurs [19]. In cases of liver cirrhosis, the ratio of the transverse diameter of caudate lobe to that of the right lobe of liver becomes equal or more than 0.65 [3]. The measurements of the parameters of the caudate lobe of the liver in the present study were compared with the results of Sahni et al., [8]. Chavan and Wabale [3], and Arora et al., [14] as shown in Table (2).

Table (2): Showing the comparison of the various measurements of the caudate lobe of the liver specimens in different studies.

\begin{tabular}{|c|c|c|c|c|}
\hline $\begin{array}{l}\text { Range of } \\
\text { measurements (mm) }\end{array}$ & Sahni et al. [8] & $\begin{array}{l}\text { Chavan and } \\
\text { Wabale [3] }\end{array}$ & Arora et al. [14] & Present study \\
\hline Length of caudate lobe & $40-72 \mathrm{~mm}$ & $40-93 \mathrm{~mm}$ & $33.8-70.3 \mathrm{~mm}$ & $46.85-69.63 \mathrm{~mm}$ \\
\hline Transverse diameter of caudate lobe & $18-41 \mathrm{~mm}$ & $25-42 \mathrm{~mm}$ & $12-42.4 \mathrm{~mm}$ & $22.16-37.16 \mathrm{~mm}$ \\
\hline Transverse diameter of right lobe of liver & - & $67-105 \mathrm{~mm}$ & $52.9-99.3 \mathrm{~mm}$ & $73.51-115.12 \mathrm{~mm}$ \\
\hline $\begin{array}{l}\text { Ratio of transverse diameter of caudate } \\
\text { lobe to that of the right lobe } \\
\text { of the liver (CL/RL ratio) }\end{array}$ & $0.23-0.40$ & $0.28-0.46$ & $0.15-0.58$ & $0.22-0.38$ \\
\hline
\end{tabular}

The liver rarely showed variations of its fissures [20]. Sarala et al., [5] and Joshi et al., [6] revealed that the caudate lobe showed longitudinal fissure on its inferior border in $30 \%$ of livers while in the present study the caudate lobe showed longitudinal fissure on its inferior border in $26.79 \%$ of livers and in $14.29 \%$ of livers other accessory fissures were seen. During imaging of the liver, these accessory fissures may result in errors of diagnosis due to collection of fluid in these fissures and may be diagnosed as cystic lesion or liver abscess [21].

In a study of 36 liver specimens, the caudate process was prominent at the right part of the lower border of the caudate lobe in $100 \%$ of liver specimens [14] and the same observation was present in this work. In some studies, the papillary process of the liver was prominent at the left part of the lower border of the caudate lobe in $21 \%$ of liver specimens [5], in $32 \%$ of liver specimens [6] and in $33.5 \%$ of liver specimens [8], while in the present study, the papillary process was prominent in $42.86 \%$ of liver specimens. Auh et al., [22] reported that during CT scans, small or normal sized papillary process may simulate enlarged lymph nodes in the porta hepatis. Auh et al., [22] added that the stomach antrum and the duodenum displaced anteriorly by enlarged papillary process and may simulate a retroperitoneal mass in the right side of the human body during CT imaging. Also, Nayak [23] revealed that the papillary process of the liver was large in $1.81 \%$ of liver specimens and in other studies enlarged papillary process was $4.29 \%$
[24] while in the present study only three liver specimens $(5.36 \%)$ showed a large papillary process.

In conclusion, variable shapes of the caudate lobe of the liver specimens were present in this work and the most common shape was rectangular. The determination of the ratio of the transverse diameter of caudate lobe to that of the right lobe of the liver (CL/RL) is important to diagnose the liver cirrhosis and in this study the mean of (CL/RL) ratio was $0.30 \pm 0.03$. Identification of accessory fissures of the caudate lobe is very important to avoid false diagnosis of the cystic lesions of the liver. These data may be valuable for radiologists and surgeons to assist in proper planning of hepatic surgery.

\section{References}

1- STANDRING S.: Gray's Anatomy E-Book: The Anatomical Basis of Clinical Practice, 41 th ed., Elsevier Health Sciences, pp. 1160-72, 2015.

2- SARITHA S., RAMANI, NAGAJYOTHI and YESENDER: Cadaveric Study of Morphological Variations in the human liver and its Clinical importance. International Journal of Medical Science and Clinical Inventions, 2 (6): 1020-31, 2015.

3- CHAVAN N.N. and WABALE R.N.: Morphological study of caudate lobe of liver. Indian Journal of Basic and Applied Medical Research, 3 (3): 204-11, 2014.

4- PATIL S., SETHI M. and KAKAR S.: Morphological study of human liver and its surgical importance. Int. J. Anat. Res., 2 (2): 310-14, 2014. 
5- SARALA H.S., JYOTHILAKSHMI T.K. and SHUBHA R.: Morphological variations of caudate lobe of the liver and their clinical implications. Int. J. Anat. Res., 3 (2): 980-3, 2015.

6- JOSHI S.D., JOSHI S.S. and ATHAVALE S.A.: Some interesting observations on the surface features of the liver and their clinical implications. Singapore Med. J., 50 (7): 715-9, 2009.

7- XU L.N. and HUANG Z.Q.: Resection of hepatic caudate lobe hemangioma: Experience with 11 patients. Hepatobiliary pancreat Dis. Int., 9 (5): 487-91, 2010.

8- SAHNI D., JIT I. and SODHI L.: Gross Anatomy of the caudate lobe of the liver. J. Anato. Soc. India, 49 (2): 123-6, 2000.

9- MEIRELLES G.D.S.P., TIFERES D.A. and D'IPPOLITO G.: Pseudolesões hepáticas na ressonância magnética: Ensaio iconográfico. Radiologia Brasileira, 36 (5): $305-$ 9, 2003.

10- NAGATO A.C., SILVA M.A.S., TRAJANO E.T.L., ALVES J.N., BANDEIRA A.C.B., FERREIRA T.A., et al.: Quantitative and morphological analyses of different types of human liver. J. Morphol. Sci., 28 (4): 275-9, 2011.

11-DEV G., SHARMA R. and SHARMA B.: Hepatic Papillary Process-An Anatomic Variant of Liver. JK. Science, 16 (4): 184-5, 2014.

12- SAHNI D., HARJEET, CHAWLA Y.K. and JIT I.: Gross anatomy of the retrohepatic segment of the inferior vena cava in northwest Indians. Indian J. Med. Res., 124: 6370, 2006.

13- SAGOO M.G. and AGNIHOTRI G.: The Retrohepatic segment of inferior vena cava and the ostia venae hepaticae in a Northwest Indian population. Braz. J. Morphol. Sci., 26 (3-4): 141-4, 2009.

14- ARORA N.K., SRIVASTAVA S., HAQUE M., KHAN A.Z. and SINGH K.: Morphometric Study of Caudate
Lobe of Liver. Ann. Int. Med. Den. Res., 2 (1): 275-9, 2016.

15- CHAMPETIER J., YVER R., LÉTOUBLON C. and VIGNEAU B.: A general review of anomalies of hepatic morphology and their clinical implications. Anat. Clin., 7: 285-99, 1985.

16- VINNAKOTA S. and JAYASREE N.: A New Insight into the Morphology of the Human Liver: A Cadaveric Study. ISRN Anatomy, Article ID 689564, 6 pages, 2013.

17- GIORGIO A., AMOROSO P., LETTIERI G., FICO P., DE STEFANO G., FINELLI L., et al.: Cirrhosis: Value of caudate to right lobe ratio in diagnosis with US. Radiology, 161 (2): 443-5, 1986.

18- AKTAN Z.A., SAVAS R., PINAR Y. and ARSLAN O.: Lobe And Segment Anomalies Of the Liver. J. Anat. Soc. India, 50 (1): 15-6, 2001.

19- AWAYA H., MITCHELL D.G., KAMISHIMA T., HOLLAND G., ITO K. and MATSUMOTO T.: Cirrhosis: Modified Caudate-Right Lobe Ratio. Radiology, 224: 769-74, 2002.

20- MACCHI V., PORZIONATO A., PARENTI A., MACCHI C., NEWELL R. and DE CARO R.: Main accessory sulcus of the liver. Clin. Anat., 18 (1): 39-45, 2005.

21- AUH Y.H., RUBENSTEIN W.A., ZIRINSKY K., KNEELAND J.B., PARDES J.C., ENGEL I.A., et al.: Accessory fissures of the liver: $\mathrm{CT}$ and sonographic appearance. AJR., 143 (3): 565-72, 1984.

22- AUH Y.H., ROSEN A., RUBENSTEIN W.A., ENGEL I.A., WHALEN J.P. and KAZAM E.: CT of the papillary process of the caudate lobe of the liver. AJR., 142 (3): 535-8, 1984.

23- NAYAK B.S.: A Study on the Anomalies of Liver in the South Indian Cadavers. Int. J. Morphol., 31 (2): 658-61, 2013.

24- SINGH H.R. and RABI S.: Study of morphological variations of liver in human. Translational Research in Anatomy, 14: 1-5, 2019.

\section{التنوعات الشكليه وقياسات الفص المذيل للكبد البشرى؛ دراسلة على الجثيه}

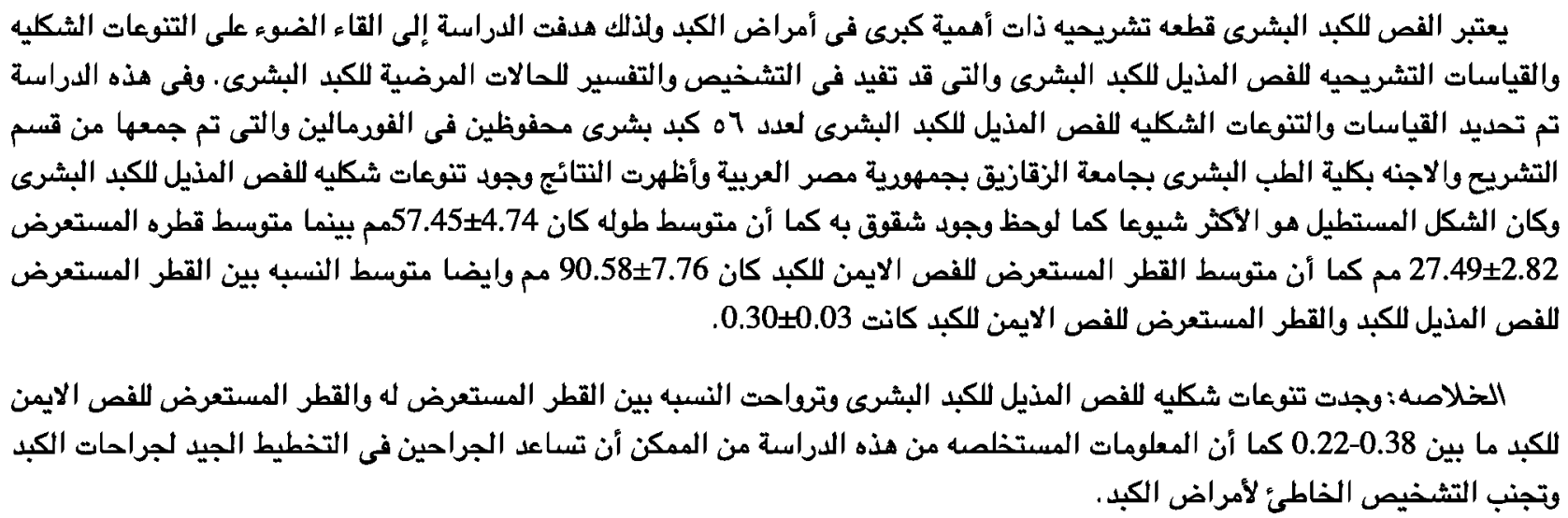

